\title{
Network investment under legal and ownership unbundling ${ }^{1}$
}

\author{
Helmuth Cremer ${ }^{2}$, Philippe De Donder ${ }^{3}$ \\ Toulouse School of Economics (IDEI and GREMAQ) \\ 21 Allée de Brienne \\ 31015 Toulouse Cedex 6
}

First version: October 2011

Revised version: November 2012

\footnotetext{
${ }^{1}$ A preliminary version of this paper has circulated under the title "Legal vs Ownership Unbundling in Network Industries". Jacques Crémer contributed to the development of the ideas presented in this paper. We thank Tine De Schutter for her comments on a previous version. We are grateful to GDF-Suez for its financial support.

${ }^{2}$ helmuth.cremer@tse-fr.eu

${ }^{3}$ Corresponding author. Email: philippe.dedonder@tse-fr.eu; Ph.: (+33) 561128542; Fax: $(+33) 561128637$
} 


\begin{abstract}
We consider an industry where an upstream firm determines the size of a network used by two downstream firms. We contrast ownership unbundling and legal unbundling, where the upstream firm maximizes its total profit, including the profit of its downstream subsidiary(ies), but does not discriminate between them. Furthermore, each downstream subsidiary maximizes its own profit. We show that ownership separation is more detrimental to welfare than legal unbundling, whether the downstream market is perfectly competitive or not, and whether there are asymmetries in network needs across downstream firms, and downstream investments, or not.
\end{abstract}

Keywords: vertical integration, upstream downstream unbundling.

JEL Codes: L14, L43, L51 


\section{Introduction}

This paper studies the impact of legal unbundling vs ownership unbundling on the incentives of a network operator to invest. We consider an industry where the upstream firm invests in and maintains a network, while several downstream firms compete in selling goods and services that use this network as a necessary input (i.e., no bypass technology is available, at least at an economically relevant price $\left.^{1}\right)$. Many network industries fit this description, including telecommunications, railways, electricity, postal sector, natural gas, etc.

There are many papers in the regulation, industrial economics and economics of organizations literature that study the impact of various ownership structures in network industries. The simplest such structure is one in which an upstream firm provides an input to a downstream firm. These papers often compare the behavior of a vertically integrated firm with the equilibrium situation where the upstream and downstream activities are undertaken by separate firms (i.e., firms whose ownership differ from one another). ${ }^{2}$

There are two types of considerations that might induce the upstream and downstream firms to merge. First, they might want to use the combined weight of the two firms for strategic purposes. For instance, when the upstream firm has market power in the supply of the input, but the downstream firm faces competition, the merger can be a way to prevent a form of "trickling up" effect of competition. We will call this view the "antitrust perspective", as it is the fear of this type of consequences that prompts competition authorities to disallow some mergers. Second, there might be some efficiency gains to running the two firms as a single unit, and the aim of the merger is to take advantage of these efficiency gains. This type of merger can arise in a competitive market, whereas the first type could not. To stress the fact that authors who write on this topic are interested in the internal functioning of the firm, we will label this branch of the literature the "managerial perspective"

In this paper, we consider a situation with one upstream firm and two competing downstream firms. Regulatory practice has typically analyzed the ownership of a downstream firm by the upstream firm in the antitrust perspective and with suspicion: this ownership is seen as an open door to anti-competitive discrimination; we think that it is fair to say that regulators have often accepted vertical integration as a political compromise. The aim of this paper is to begin exploring what the managerial perspective can bring to

\footnotetext{
${ }^{1}$ We relax this assumption in section 6 .

${ }^{2}$ See for instance the seminal paper by Vickers (1995) or the more recent one by Brito et al. (2010) and the references therein.
} 
the debate.

What the managerial perspective calls vertical disintegration corresponds to the ownership unbundling scenario that we study in the current paper. There also exists an intermediate (between integration and full divestiture) form of unbundling, often called legal unbundling. This corresponds to the situation where the upstream and one or many downstream firms belong to the same owners and where these owners, although they are the residual claimants over the financial returns generated by the firms' assets (i.e., they keep the firms's profits), do not have the full control rights over the firms' decisions.

Legal unbundling appears for instance in several European directives on network industries. For instance, the 2003/55 European Directive on natural gas states "In order to ensure efficient and non-discriminatory network access it is appropriate that the transmission and distribution systems are operated through legally separate entities where vertically integrated undertakings exist. It is important however to distinguish between such legal separation and ownership unbundling. Legal separation implies neither a change of ownership of assets [...]. However, a non-discriminatory decision-making process should be ensured through organizational measures regarding the independence of the decision-makers responsible." The Directive especially stresses the independence of the upstream firm (called the "transmission system operator") from "day to day operation of the production, distribution and supply of natural gas". 3

While it is clear how ownership unbundling can guarantee the independence of decisions between upstream and downstream firms, it is far less clear how to model the objective functions of these two types of firms in the case of legal unbundling. We proceed as follows. We consider a sequential game where the upstream firm first chooses the size of its network, and where two downstream firms then compete by selling goods that use this network as an essential input. We contrast the (socially) optimal allocation with several equilibrium situations, depending on the ownership structure in the indus-

\footnotetext{
${ }^{3}$ The more recent 2009/73/EC Directive, which repeals 2003/55, takes a dimmer view of legal unbundling (stating in its Whereas (7) that "The rules on legal and functional unbundling as provided for in Directive 2003/55/EC have not, however, led to effective unbundling of the transmission system operators"), but falls short of imposing full ownership unbundling. Rather, it states in its Whereas (13) that "the setting up of a system operator or a transmission operator that is independent from supply and production interests should enable a vertically integrated undertaking to maintain its ownership of network assets whilst ensuring an effective separation of interests" and that "Member States should therefore be given a choice between ownership unbundling and setting up a system operator or transmission operator which is independent from supply and production interests."
} 
try. More precisely, we consider the market equilibria when the upstream firm owns zero, one or two downstream firms. The first situation corresponds to ownership unbundling between upstream and downstream parts of the market. As for the other two cases, we equate legal unbundling with the following two assumptions. First, each downstream firm maximizes its own profit, without taking into account any impact on the upstream firm's profit. Second, the upstream firm is not allowed to discriminate between downstream firms by charging different access charges for the use of its network. On the other hand, we assume that the upstream firm chooses its network size in order to maximize its total profit, including the profit of its downstream subsidiaries.

Our modeling choice for legal unbundling and for regulation needs to be explained at this stage. We assume that legal unbundling is effective in ensuring that the upstream firm does not use its power to favor its downstream affiliate(s), and thus promotes competition downstream among the firms using the network to provide final goods and services. We then abstract from the discrimination/sabotage concerns studied by the antitrust literature. At the same time, it appears to us much more difficult to ensure that network investments do not take into account the profit of the whole group in case of legal unbundling. ${ }^{4}$ In other words, we take a long-term perspective where the lack of downstream competition and the ability of the upstream firm to discriminate between downstream firms have been solved by the requirement of legal unbundling, and we concentrate on the way legal unbundling may distort the network investment decisions. This view explains the absence of explicit regulation in our setting, where the access charge is not regulated, but set endogenously at the market-clearing level once the network size has been chosen. This may not correspond to the practice in most network industries, where the regulator often affects the level of the access charges. ${ }^{5}$ We rather look at the objectives of regulators (absence of downstream discrimination and downstream competition), and we focus on the best case scenario where they are satisfied so that we concentrate on studying how ownership arrangements affect investment incentives in this environment.

With ownership unbundling, the upstream firm sets a lower-than-optimal network level in order to increase the equilibrium access charge and maximize

\footnotetext{
${ }^{4}$ If network investment were also taken independently, so that they maximized only the upstream profit, there would be no difference between vertical separation and unbundling in our setting.

${ }^{5}$ Although there are exceptions, such as the UK postal sector, the energy market in Germany in the beginning of the 2000s, or natural gas storage facilities in the European Directive, where access charges are negotiated between the owner of the network and firms demanding access to it.
} 
its profit. With legal unbundling, the upstream firm takes into account downstream profits as well. If these profits are increasing in network size, legal unbundling then mitigates the incentive of the upstream firm to invest too little in the network. ${ }^{6}$ In order to show this, we present four different models. After introducing our general framework in section 2, in section 3 we explore the strategies of the firms when the two downstream firms face the same cost functions, use the network with the same intensity and are price takers on the market for the final output (on which they sell their production). Section 4 revisits the same model assuming that the firms have the same "non-network" cost function, but have different network utilization requirements. In section 5, we relax the assumption that the downstream market is competitive. Section 6 assumes that the downstream firms can make some investments that reduce their use of the network at given output. This may be interpreted, for instance, as investing in bypass activities. In all these cases, we obtain the same results: disallowing joint ownership of network and downstream facilities reduces the investment in the network. The conclusion, section 7 , discusses the limits of our work and the extensions that would be necessary for a more complete comparison of legal and ownership unbundling.

We would like to stress that our objective is to highlight one specific aspect of the comparison between ownership and legal separation, namely its impact on the incentives to invest in the network. We certainly do not claim that integration is always better than separation, but only that this particular effect should be taken into account by policy makers when assessing the pros and cons of the various ownership arrangements.

Before moving to the model, we mention briefly the related literature.

\section{Related literature}

Our paper is related to different strands of literature, including the ones on vertical integration and separation (see footnote 2 above), the role of ownership in the theory of the firm (see Alchian and Demsetz (1972) and Grossman and Hart (1986)), and the regulation of infrastructure (see the review by Guthrie (2006) and the references therein, as well as Buehler et al.(2004) for a comparison of the network provider's incentives to invest in infrastructure quality under vertical integration and separation). Due to space constraints,

\footnotetext{
${ }^{6}$ The linearity of the access charge is crucial to our results, since a non-linear access charge (such as a two-part tariff) would allow the usptream firm to capture all downstream profits at no efficiency cost, whatever the ownership arrangement. In other words, the inefficiency comes from the fact that downstream firms base their decisions on the distorted linear access charge, rather than the true marginal cost of access.
} 
we concentrate in this section on the emerging literature dealing with legal separation. These papers differ in the way they model legal unbundling.

Sibley and Weisman (1998) examine the situation where a regulated upstream firm provides an input to firms in the downstream market. The paper derives numerical conditions under which the upstream monopoly entering the downstream market has no incentive to discriminate against its downstream competitors, because it would hurt the selling of access more than it would benefit its subsidiary. What qualifies this paper as a member of the legal separation literature is its second part, where it studies and compares two ways to condition the monopoly's entry into the downstream market: with a "fully separated subsidiary" maximizing its own profit and buying the input at the same price as its downstream rivals, or as a fully integrated firm maximizing total profits and subject to an imputed price floor in the downstream market. The paper shows that no solution always dominates the other in terms of incentives to discriminate.

Bolle and Breitmoser (2006) posit that regulation is less effective with legal than ownership unbundling (because of the profit transfers that are possible between upstream and downstream firms under legal unbundling), but that legal unbundling solves the double marginalization problem associated with ownership unbundling. The paper then studies under what circumstances this trade-off results in a lower price for consumers under legal unbundling. van Koten (2008) studies electricity markets where auctions are used and shows that, even if legal unbundling is successful in preventing discriminatory treatment of buyers, it may nevertheless result in distorted bidding incentives, leading the integrated buyer to be more aggressive than with ownership unbundling (because, even if the legally unbundled seller can be restricted to maximize its own profit, the buyer can be instructed by the holding company to maximize total joint profits). The three papers closer to ours are Höffler and Kranz (2011a, b) and Fiocco (2011). Like us, they model a market with one firm upstream and several downstream. In their setting, contrary to ours, one downstream firm owns the upstream firm. Höffler and Kranz (2011a, b) assume that the regulator cannot prevent the upstream firm from using nontariff discrimination in favor of its parent. They study and compare market equilibria when the access charge has been exogenously set by a regulator. Höffler and Kranz (2011a) study perfect legal unbundling, where the downstream firm maximizes joint profits while the upstream firm maximizes its own profit. They show that legal unbundling never yields lower quantities in the downstream market than ownership separation and integration. Höffler and Kranz (2011b) study imperfect legal unbundling, where the upstream firm is biased and also takes part of the downstream firm's profit under consideration. 
They show how the extent of this bias affects total output, and how the bias can be endogenized as a function of ownership shares. Fiocco (2011) studies the optimal (regulated) access charge under asymmetric information regarding the upstream cost. In that setting, legal unbundling looks very much alike vertical integration (both the downstream incumbent and its upstream subsidiary maximize their joint profit), except that the regulator has to guarantee non negative profits to both firms under legal unbundling. The author shows that legal unbundling may dominate ownership separation because it creates countervailing incentives within the vertical group to strategically use its information. The current paper differs from this literature mainly by abstracting from discrimination and sabotage considerations.

\section{The model}

Consider an industry where one firm (referred to as "upstream", indexed by $U$ ) is in charge of building and maintaining a network, while two firms ("downstream", indexed by $i=1,2)$ sell goods or services that use the network. The upstream firm chooses the size $l$ of the network it builds and maintains. The (constant) per-unit cost of the network is denoted by $k$, so that its total cost is $K=k l$. Downstream firm $i$ sells $x_{i}$ units of its product at price $p_{i}$. Production technology is such that each unit of good $i$ uses one unit of network: there is no bypass technology available at an economically relevant cost, so that the network is an essential facility. In addition to network costs, both downstream firms have the same (non network related) cost function $C\left(x_{i}\right)$. We assume that the downstream technology shows decreasing returns to scale, so that $C^{\prime}\left(x_{i}\right)>0$ and $C^{\prime \prime}\left(x_{i}\right)>0 .^{7}$ To ensure concavity of the profit functions, we will also often assume that $C^{\prime \prime \prime}\left(x_{i}\right)$ is positive. As for the network costs, downstream firms pay to the upstream firm a constant access charge $a$ (that is endogenous in our model, and not set by a regulator) for each unit of the network that they use.

The products sold by both downstream firms are perfect substitutes. ${ }^{8}$ Let $X$ denote the total quantity in the downstream market, so that $X=$ $x_{1}+x_{2}$. We denote by $X(p)$ the aggregate demand for the downstream product, and by $p(X)$ the aggregate inverse demand. We assume that the revenue

\footnotetext{
${ }^{7}$ This assumption guarantees that competitive downstream firms earn a positive profit, which is crucial to our argument. This assumption is relaxed in section 5 where we introduce imperfect downstream competition.

${ }^{8}$ This assumption is not crucial: our results would carry through if the downstream goods were sold on totally separate, unrelated markets or if they were imperfect substitutes.
} 
functions $p X(p)$ and $X p(X)$ are concave. We denote by $\pi_{U}$ the upstream firm's profit and by $\pi_{i}$ downstream firm $i$ 's profit.

We model the following sequential game: first, the upstream firm chooses the size of the network and then the downstream firms compete. This timing is natural given the nature of the decisions involved. We solve this game for various scenarios concerning the downstream competitive conditions and the symmetry between downstream firms. In Sections 3, 4 and 6, we assume that the downstream firms are perfectly competitive (price takers). Consequently, they choose their output level to equate marginal cost and market price. Section 3 is concerned with the case where both downstream firms are symmetrical: they share the same downstream cost function and have the same needs in terms of network usage. Section 4 considers the case where the network is more adapted to one of the downstream firms than to the other, while the non network related cost functions of the two downstream firms are the same. Section 6 analyzes the impact of allowing downstream firms to also make investments that would allow them to decrease their need of network usage for any given output level. Section 5 lifts the assumption that downstream firms are pure price takers but rather assumes that they have market power and play a Cournot game.

We proceed similarly in Sections 3 to 6 . We first study the surplusmaximizing allocation. We then solve the model by backward induction, starting with the downstream equilibrium, to obtain prices (including the access charge) and quantities as a function of the network size. We then study the equilibrium choice by the upstream firm of the network size as a function of the ownership structure. Under ownership separation, firm $U$ chooses the network size $l$ that maximizes $\pi_{U}$, anticipating downstream firms' reactions. Under legal separation, firm $U$ chooses the network size $l$ that maximizes $\pi_{U}+\pi_{i}$ if it owns only downstream firm $i$, and $\pi_{U}+\pi_{1}+\pi_{2}$ if it owns both. ${ }^{9}$ In both cases, downstream firms maximize their own profit. Recall that legal separation prevents the upstream firm from taking downstream decisions directly. Our objective is to assess how legal and ownership unbundling affect the equilibrium network size. ${ }^{10}$

\footnotetext{
${ }^{9}$ This is a specific way to model legal unbundling. Other approaches are possible and might lead to other results. For instance one could assume that it's the downstream firm which maximizes total profits while the upstream firm is only concerned with its own profit.

${ }^{10}$ The upstream firm, by choosing the network size, determines the final quantity. This implies (as long as social surplus is increasing in quantity below the efficient level) that larger investments yield higher social surplus. Observe that the upstream firm also determines the access charge that clears the market for capacity.
} 


\section{$3 \quad$ Symmetric Equilibria}

We begin by studying the outputs that would be chosen by a welfare-maximizing planner before turning to the analysis of the game between the firms.

\subsection{Social Optimum}

The social optimum is the allocation that maximizes total surplus $S$ in the economy. Assuming quasi-linear preferences for consumers of the downstream products, total surplus is equal to consumers gross surplus minus upstream and downstream costs. The social planner chooses a network size $l$ that solves

$$
\max _{l} S=\int_{0}^{l} p(s) d s-2 C\left(\frac{l}{2}\right)-k l .
$$

Denote the optimal level of variables by $\mathrm{a}^{*}$. The solution is given by $x_{1}^{*}=$ $x_{2}^{*}=X^{*} / 2$ where $X^{*}=l^{*}$ is defined by

$$
p\left(X^{*}\right)=C^{\prime}\left(\frac{X^{*}}{2}\right)+k=C^{\prime}\left(x_{i}^{*}\right)+k .
$$

This condition is easy to interpret; it requires marginal cost to equal marginal willingness to pay for the final good. The marginal cost is equal to the sum of marginal upstream and downstream costs. Further, observe that, at the optimum, the marginal cost is the same for both firms. ${ }^{11}$ The optimal network size equals the volume of goods sold at this optimal price.

\subsection{Equilibrium}

In the remainder of this section, we shall study different ownership structures. For all of them, once the size of the network has been chosen, the downstream firms act as price-takers. Solving the game by backward induction, we first study the prices which will prevail given a choice of a network size $l$.

Because the downstream firms are price-takers, they consider both the market price $p$ of their output and the network access $a$ as given. Consequently, they choose their output in order to equalize their marginal cost with the market price $p$ :

$$
p=C^{\prime}\left(x_{i}\right)+a
$$

\footnotetext{
${ }^{11}$ This will hold true also when we introduce an asymmetry between the downstream firms. In other words, productive efficiency is necessary for social optimality.
} 
Their total production will be $X(p)$, which is equal to their total demand for the services of the network since equilibrium on the network input market requires

$$
X(p)=l .
$$

Given a size $l$ chosen for the network in the first stage of the game, equations (2) and (3) simultaneously determine the access charge $a$ and the downstream price $p$ (and therefore also the quantity sold $X$ ) as functions of $l$; we denote these functions by $\tilde{a}(l)$ and $^{12} \tilde{p}(l)=p(l)$ : they denote the prices that will prevail as a function of the choice of $l$.

We now turn to the capacity decision by the upstream firm whose profit is given by

$$
\pi_{U}=\widetilde{a}(l) l-k l,
$$

while the profit functions of the two downstream firms, $\pi_{1}$ and $\pi_{2}$, are

$$
\pi_{i}=x_{i}(\widetilde{p}(l))[\widetilde{p}(l)-\widetilde{a}(l)]-C\left(x_{i}(\widetilde{p}(l))\right), \quad i=1,2,
$$

where $\tilde{a}(l)$ and $\tilde{p}(l)$ are the solutions to equations (2) and (3).

Observe that firm $U$ has some market power, since it anticipates the equilibrium downstream prices (access charge $a$ and final price $p$ ) induced by its choice of $l$. Further, the assumption that $C^{\prime \prime}\left(x_{i}\right)>0$ means that downstream firms make a positive profit even when they act as price takers.

We introduce the following notation to compare the various scenarios studied. We use the superscript $e 2$ to index the equilibrium levels of the different variables when the upstream firm owns the two downstream firms, the superscript $e 1$ when it owns only one, and the superscript $e 0$ when it owns none (the ownership unbundling scenario).

The proof of the following proposition is provided in the Appendix.

Proposition 1 Assume that downstream firms are symmetrical. Then

(a) The equilibrium when the upstream firm owns both downstream firms while subject to legal unbundling is the same as the one with vertical integration;

(b) We have

$$
l^{e 0}<l^{e 1}<l^{e 2}<l^{*} .
$$

\footnotetext{
${ }^{12}$ Notice the difference: $p(l)$ represents the price at which consumers will choose to consume $l$ units of the final good whereas $\tilde{p}(l)$ represents the price which will prevail if $l$ units of network services are provided. In the model of this section, they are equal; with other technology of productions they need not be.
} 
The scenario of legal unbundling (where $U$ chooses the network size to maximize the sum of upstream and of both downstream profits) differs from the classical vertical integration case because the upstream firm $U$ does not control the pricing policy of the two downstream firms. In other words, the managers of the downstream firms maximize their profit given the market price. Proposition 1 (a) shows that we nevertheless obtain the same allocation in both cases. In both cases, the upstream firm chooses the network size (and thus the total retail output) to equalize marginal revenue and marginal cost, with marginal cost being the sum of the downstream marginal cost $C^{\prime}$ and of the upstream marginal cost $k$, rather than the access charge paid by the downstream firm. In other words, when setting its network size, the upstream firm understands that the access charge is a pure transfer between its subsidiary and itself.

We now move to the comparison of the equilibrium allocation in that case with the socially optimal one. Proposition 1 (b) shows that the equilibrium network size is lower than socially optimal with legal unbundling $\left(l^{e 2}<l^{*}\right)$ so that the equilibrium retail price is larger than optimal $\left(p^{e 2}>p^{*}\right)$. Intuitively, the upstream firm chooses a lower-than-optimal network size in order to reduce the downstream output level and to increase downstream profits. This result holds even with legal unbundling between downstream and upstream firms -i.e., even when managers of the downstream firms do not take into account the profits of the upstream firm when they set their profit-maximizing prices.

Proposition 1 (b) shows that the underprovision of network is even larger with ownership unbundling $\left(l^{e 0}<l^{e 2}<l^{*}\right)$ : the fact that the upstream firm does not share in the downstream profits induces it to further decrease $l$ and $X$, compared to the legal unbundling situation. Ownership unbundling is thus more detrimental to welfare than legal unbundling in our setting. The driver for this result is the assumption of decreasing returns to scale. With $C^{\prime \prime}>0$, downstream profits (which equal $C^{\prime}\left(x_{i}\right) x_{i}-C\left(x_{i}\right)$ because of pricetaking behavior on the downstream market) are not only positive but also increasing in $x_{i}=l / 2$. The upstream firm does not capture these downstream profits with ownership unbundling, unlike with legal unbundling. This in turn means that increasing the network size is less attractive for the upstream firm under ownership separation, leading to $l^{e 0}<l^{e 2}$.

Finally, the scenario $e 1$ (where the upstream firm owns one downstream firm) gives a profit-maximizing size of the network that is intermediate between scenarios $e 0$ (ownership separation) and $e 2$ ( $U$ owns both downstream firms). This results is straightforward since the objective function of $U$ under $e 1$ is a 
convex combination of the objectives under $e 0$ and $e 2$ :

$$
\pi_{U}+\pi_{i}=\frac{1}{2}\left(\pi_{U}+\pi_{1}+\pi_{2}\right)+\frac{1}{2} \pi_{U} \quad, i=1,2
$$

To summarize, we have established that the incentives for the proper determination of the network size increase with the number of downstream firms that the upstream firm owns. The main driver for this result is the decreasing returns to scale on the downstream market, which ensure that downstream profits (not captured by firm $U$ under ownership separation) are increasing in network size. As the upstream firm acquires more downstream firms, its incentives to invest in the network increase, and the equilibrium network size increases toward the optimal level. Observe that we have assumed throughout the analysis that legal unbundling prevails in the absence of ownership unbundling. We have also obtained that, with legal unbundling, the equilibrium network size when the upstream firm owns both downstream firms falls short of the optimal network size.

\section{Downstream firms' asymmetry}

We now introduce some asymmetry between downstream firms, in the form of different needs in terms of network access. We assume that the investments made in the network by the upstream firm benefit more one firm than the other. For instance, in the natural gas sector, this situation could arise because of the localization of the investments (new pipelines built in a region where one downstream firm has a larger share of its customers' portfolio than the other firm) or their type (investing in LNG rather than pipelines for instance). The objective in this section is to understand how the existence of such asymmetries affects the optimal and equilibrium size of the network, and how it relates with legal and ownership unbundling.

We model asymmetry in network needs as follows. We assume that downstream firm 1 benefits more than downstream firm 2 from investments in the network: firm 1 needs only $(1-\alpha)$ unit of network for each unit of final good that it sells. On the other hand, downstream firm 2 needs one unit of network use for each unit of final good sold, as previously. The parameter $\alpha \in[0,1$ [ measures the intensity of the additional benefit that firm 1 gets from the network. We assume that this parameter $\alpha$ is set exogenously (given by the technology, for instance). An extension to our analysis would be to endogenize the setting of this parameter by letting the upstream firm choose its profit-maximizing level. 
Except for the introduction of the parameter $\alpha$, we maintain all the assumptions made in the previous section. We proceed as in the previous section by looking first at the optimal allocation before turning to the equilibrium allocations in the various unbundling scenarios.

\subsection{Social Optimum}

The social planner's optimization program is

$$
\max _{x_{1}, x_{2}} S=\int_{0}^{x_{1}+x_{2}} p(s) d s-C\left(x_{1}\right)-C\left(x_{2}\right)-k\left[(1-\alpha) x_{1}+x_{2}\right],
$$

yielding the following first-order conditions

$$
\begin{aligned}
& p\left(x_{1}+x_{2}\right)=C^{\prime}\left(x_{1}\right)+(1-\alpha) k, \\
& p\left(x_{1}+x_{2}\right)=C^{\prime}\left(x_{2}\right)+k .
\end{aligned}
$$

These are the usual conditions that price should equal marginal costs. Together, they imply that

$$
C^{\prime}\left(x_{1}^{*}\right)+(1-\alpha) k=C^{\prime}\left(x_{2}^{*}\right)+k,
$$

i.e., that we have productive efficiency at the optimum.

The first-order conditions allow us to obtain the optimal downstream quantities and network size, which we denote as previously with a ${ }^{*}: x_{1}^{*}, x_{2}^{*}$ and $l^{*}=(1-\alpha) x_{1}^{*}+x_{2}^{*}$.

\subsection{Equilibrium}

As in section 3, we need to compute the equilibrium of the game played by the downstream firms as a function of $l$.

Competition in the downstream market generates the following equilibrium conditions, which replace (2) and (3):

$$
\begin{aligned}
& p=C^{\prime}\left(x_{1}\right)+a(1-\alpha), \\
& p=C^{\prime}\left(x_{2}\right)+a, \\
& l=(1-\alpha) x_{1}+x_{2}, \\
& X(p)=x_{1}+x_{2} .
\end{aligned}
$$

The solution to these four simultaneous equations yields the equilibrium levels of the access charge, retail price and downstream quantities as functions of the 
network size and the parameter $\alpha$. Given that $\alpha$ is treated as exogenous in this section, we denote these relationships by $\widetilde{a}(l), \widetilde{x}_{1}(l), \widetilde{x}_{2}(l)$ and

$$
\widetilde{p}(l)=p\left(\widetilde{x}_{1}(l)+\widetilde{x}_{2}(l)\right) .
$$

Observe that, unlike in the earlier section, we now have that $\widetilde{p}(l) \neq p(l)$ since $l \neq x_{1}+x_{2}$.

We make use of the equilibrium quantities and price in the downstream markets to obtain the profit levels of the three operators as a function of the network size:

$$
\begin{aligned}
& \pi_{U}=\widetilde{a}(l) l-k l, \\
& \pi_{1}=\widetilde{x}_{1}(l)[\widetilde{p}(l)-(1-\alpha) \widetilde{a}(l)]-C\left(\widetilde{x}_{1}(l)\right), \\
& \pi_{2}=\widetilde{x}_{2}(l)[\widetilde{p}(l)-\widetilde{a}(l)]-C\left(\widetilde{x}_{2}(l)\right) .
\end{aligned}
$$

When comparing the allocations under the various ownership scenarios, we now have to distinguish between the case where the upstream firm owns the downstream firm 1 (denoted by $e 11$ ) and the case where $U$ owns firm 2 (denoted by e12). The proof of the following proposition is provided in the Appendix.

Proposition 2 Assume that downstream firms are asymmetrical in their network needs. Then

(a) The equilibrium when the upstream firm owns both downstream firms while subject to legal unbundling differs from the one with vertical integration;

(b) Legal unbundling results in production inefficiency;

(c) We have

$$
l^{e 0}<l^{e 11}<l^{e 2} \text { and } l^{e 0}<l^{e 12}<l^{e 2} .
$$

Under scenario $e 2$, the upstream firm maximizes total profit by equating the marginal revenue of increasing downstream output with the relevant marginal cost (see equation (A9) in the Appendix). The relevant marginal non-network cost is a convex combination of the two marginal non-network costs, with the weight put on any firm $i$ 's marginal cost equal to the proportion that this firm's additional output represents in the total additional downstream output when the network size is increased: $\widetilde{x}_{i}^{\prime}(l) /\left(\widetilde{x}_{1}^{\prime}(l)+\widetilde{x}_{2}^{\prime}(l)\right)$. The marginal network cost of downstream units is now smaller than $k$, since firm 1's output uses less than one unit of network. This stands in stark contrast with 
the profit-maximizing condition for a vertically integrated monopoly, which equates separately marginal revenue with the marginal cost of each of the two downstream firms.

This means that, while under symmetry legal separation and full integration yielded the same outcome, this is no longer true here. Under legal unbundling with asymmetric downstream firms, the upstream firm does not have enough instruments to achieve the integrated solution; setting the network size is not longer sufficient to have full control.

Also, while under vertical integration productive efficiency is maintained by the fully integrated firm (since marginal costs are the same at equilibrium for the two downstream operators), there is no mechanism to equalize these marginal costs in the case of legal separation. Consequently, legal unbundling will result in production inefficiency under asymmetry.

Part (c) of Proposition 2 shows that the intuition obtained in section 3 carries over to the case of asymmetric downstream cost functions: with ownership unbundling, the upstream firm fails to take into account downstream profits, with the difference between upstream and downstream profit levels increasing with downstream volumes. The upstream firm has then an incentive to invest less in its network than in the case where it owns the two downstream firms: $l^{e 0}<l^{e 2}$. Moreover, this also explains why the network size when the upstream firm owns one downstream firm is larger than with ownership separation but smaller than when the upstream firm owns both downstream firms.

The general conclusion that we draw from this section is that the relative ranking of the equilibrium network sizes is robust to the introduction of asymmetry between downstream firms. With such an asymmetry, ownership unbundling leads to more under-investment than legal unbundling: the more integrated the industry, the closer the equilibrium network size to its optimal level.

We now study the robustness of our results to the introduction of imperfect competition in the downstream market.

\section{Imperfect competition in the downstream market}

In this section, we assume that both downstream firms compete $\grave{a}$ la Cournot on the final market. We maintain the assumption that the products they offer are perfect substitutes. We retain the assumption that they are totally symmetric: they have the same cost function and require the same use of the network. We further assume that the downstream cost function is linear, with 
$C\left(x_{i}\right)=c x_{i}$. Finally, we assume that the downstream firms act as price takers in their purchase of network services.

\subsection{Social Optimum}

The social planner's objective is to

$$
\max _{l} S=\int_{0}^{l} p(s) d s-c l-k l .
$$

The solution $X^{*}=l^{*}$ to this problem is defined by

$$
p\left(X^{*}\right)=c+k .
$$

This is the usual condition that marginal willingness to pay should equal marginal cost. Since the (constant) marginal cost is the same for both downstream firms, the socially optimal allocation is concerned with the total downstream quantities and not with the individual quantities sold by each firm.

\subsection{Equilibrium in the downstream market}

With Cournot competition, each downstream firm chooses its output level $x_{i}$ in order to maximize

$$
\begin{aligned}
\pi_{i} & =x_{i} p\left(x_{i}+x_{j}\right)-a x_{i}-c x_{i}, \\
& =x_{i}\left[p\left(x_{i}+x_{j}\right)-a-c\right],
\end{aligned}
$$

given the output level $x_{j}$ supplied by its competitor $j$. The fact that firm $i$ acts as a price taker in the market for network services implies that it takes the access charge $a$ as given, and independent of its own demand for these services.

The first-order condition for downstream profit maximization is

$$
x_{i}=\frac{p\left(x_{i}+x_{j}\right)-a-c}{-p^{\prime}\left(x_{i}+x_{j}\right)} .
$$

Equation (10) together with the condition $X(p)=l$ determine as previously the access charge and retail price as a function of network size. These relationships are denoted by $\tilde{a}(l)$ and $\tilde{p}(l)=p(l)$.

The symmetry between the two firms together with the equilibrium condition on the market for input $l$ imply that both firms choose the same output in equilibrium

$$
x_{1}=x_{2}=l / 2 .
$$


This relationship allows us to simplify equation (10) to obtain

$$
\tilde{p}(l)=a+c-\frac{l}{2} \tilde{p}^{\prime}(l),
$$

with $\tilde{p}^{\prime}(l)<0$.

The intuition for this result is that each firm sells its product at a price larger than its marginal cost $a+c$, with the mark-up being inversely proportional to (half) the demand-price elasticity of output.

We now proceed to study equilibrium network size under various integration scenarios, and we obtain the following proposition (proved in the Appendix).

Proposition 3 Assume that downstream firms compete à la Cournot. Then, we have that

$$
l^{e 0}<l^{e 1}<l^{e 2}<l^{*} .
$$

The intuition for why the network size under legal separation with two subsidiaries is lower than optimal $\left(l^{e 2}<l^{*}\right)$ is the same as previously: the upstream firm under-invests in the network in order to decrease downstream quantities and increase downstream prices. The main difference with the previous sections lies in the fact the downstream firms make a profit because of imperfect competition, not because returns to scale are decreasing.

We also obtain that the underprovision of network is even larger with ownership unbundling $\left(l^{e 0}<l^{e 2}\right)$ : as in previous sections, the upstream firm not sharing in the downstream profits induces it to further decrease $l$, compared to the legal unbundling situation, because downstream profit is increasing in network size. Although the result is the same, the mechanism that links network size with downstream profit differs. It is now due to the product of network size (or total downstream quantity) by downstream mark-up (equal to $l \tilde{p}^{\prime}(l) / 2$ by equation (11)) being increasing in $l$, thanks to the second-order condition for (total) profit maximization by the upstream firm. In other words, the reason why the downstream profit increases with the network size depends on the downstream cost structure and competitive situation: under perfect competition, it is due to the (assumed) convexity of costs while under imperfect competition, it is due to the variation in the downstream mark-up.

Finally, if the upstream firm owns one of the downstream firms, one can replicate the argument mentioned in section 3: the constraints faced are the same in the cases where the upstream firm owns zero, one and two downstream firms, while the objective in the case $e 1$ is a convex combination of the objectives in the scenarios $e 0$ and $e 2$. 
We then obtain that, provided that the profit functions are concave in $l$,

$$
l^{e 0}<l^{e 1}<l^{e 2}<l^{*} .
$$

We then conclude from this section that the ranking of network sizes according to the number of downstream firms owned by the upstream firm is robust to the introduction of imperfect competition in the downstream market.

\section{Investments by the downstream firms}

We now study the robustness of our results to the introduction of a second decision by the downstream firms, beyond the setting of their prices. This decision is how much to invest in an activity that, although costly by itself, allows the downstream firm to economize on its network usage for any given level of output. One example of such an investment would be, in the natural gas market, for the downstream firms to offer to final clients interruptible contracts or alternatively to buy insurance to cover risks such as transport congestion due to a peak demand. These two types of contracts are obviously costly for the downstream firm (in the first case because they decrease its output price, in the second because of the direct outlays they represent) but allow it to decrease its needs in terms of network usage for any level of output sold to clients. Alternatively, these investments can be seen as bypass activities, decreasing the need for access to the network at the expense of other, nonnetwork, costs.

We maintain the assumption of legal unbundling throughout the analysis, so that the upstream firm cannot control the investment decisions of its downstream subsidiaries. We model this extension to downstream investments as follows. The profit of downstream firm $i$ is given by

$$
\pi_{i}=p x_{i}-C\left(x_{i}\right)-\beta\left(y_{i}\right) a x_{i}-y_{i} x_{i},
$$

where $y_{i}$ measures the per-unit of output amount of investment made by firm $i$, and $\beta\left(y_{i}\right)$ the resulting network needs of firm $i$ by unit of output. We have that $\beta(0)=1$ and that $\beta^{\prime}\left(y_{i}\right)<0$. Also, as above, the non-network cost function $C$ is convex, with $C^{\prime \prime \prime}>0$. 


\subsection{Social Optimum}

The social planner chooses the network size $l$ and the downstream investment that solve the problem

$$
\max _{l, y} S=\int_{0}^{X} p(s) d s-2 C\left(\frac{l}{2 \beta(y)}\right)-\frac{y l}{\beta(y)}-k l,
$$

with $X=l / \beta(y)$.

Denoting the optimal level of variables by a ${ }^{*}$ as previously, the firstorder condition with respect to network size is

$$
p^{*}=p\left(X^{*}\right)=C^{\prime}\left(\frac{X^{*}}{2}\right)+y+k \beta(y)
$$

i.e., marginal willingness to pay should equal social marginal cost. With constant marginal costs, the social optimum determines total downstream output but not how much is produced by firm 1 or firm 2 . For later use, we express condition (12) in terms of mark-up over the marginal non network cost:

$$
p^{*}-C^{\prime}\left(\frac{X^{*}}{2}\right)=y+k \beta(y)
$$

The first-order condition with respect to downstream investment is

$$
\beta^{\prime}\left(y^{*}\right) k=-1 .
$$

Both firms should invest the same per-unit of output amount, which equalizes marginal benefit and marginal cost per unit of output.

\subsection{Equilibrium in the downstream market}

The two downstream firms, which are price takers both on the downstream market and on the market for the network input, simultaneously choose their profit-maximizing levels of investment, $y_{i}$. Using the symmetry between downstream firms, the first-order condition for $y$ is

$$
\beta^{\prime}(y) a=-1,
$$

which is very intuitive, since it calls for equalization of the monetary marginal benefit from the investment with its marginal cost.

The price-taking behavior of downstream firms implies

$$
p=C^{\prime}\left(\frac{X(p)}{2}\right)+a \beta(y)+y,
$$


i.e., that the equilibrium price equals total marginal cost for the downstream firms.

Equilibrium on the input $l$ market implies

$$
\beta(y) X(p)=l .
$$

Equations (15) to (17) simultaneously determine the access charge $a$, the downstream price $p$ and the amount of downstream investment $y$ (and thus also $X)$ as functions of $l$. We denote these functions by $\tilde{a}(l), \tilde{y}(l)$ and $\tilde{p}(l)$. Observe that, as in section $4, \tilde{p}(l) \neq p(l)$ because $l \neq X=x_{1}+x_{2}$.

The following proposition, whose proof is provided in the Appendix, characterizes the equilibrium as a function of the ownership scenario.

Proposition 4 Assume that downstream firms also proceed to downstream investments. Then, we have that

(a) The mark-up over the non-network cost is larger than socially optimal with legal separation and two downstream subsidiaries;

(b) We have

$$
l^{e 0}<l^{e 1}<l^{e 2}
$$

if $\tilde{x}_{i}^{\prime}(l)>0$.

The mark-up over the non-network cost when the upstream firm owns the downstream firms ( $e 2$ scenario) is socially too large for two reasons (see equation (A19) in the Appendix). The first one is the inclusion in the $e 2$ mark-up of the usual marginal revenue term, since the upstream firm takes into account how the final price is affected by its network size decision when maximizing its profit. The other component of the $e 2$ mark-up is the (per unit of output) network cost, including the investment cost. It is larger than socially optimal as soon as the access charge $a$ differs from the marginal cost of the network $k$ because downstream firms' investment decisions minimize their network cost using the former rather than the latter (compare (15) with (14)). Both effects drive the equilibrium $e 2$ mark-up above its socially optimal level.

In section 3 , the observation that the mark-up over non-network marginal cost $C^{\prime}$ was larger in the $e 2$ scenario than its optimal level was enough to deduce that $p^{e 2}>p^{*}$ and $l^{*}>l^{e 2}$. This is not sufficient in the framework of this section, since such comparisons also depend on the comparison between $y^{e 2}$ and the socially optimal downstream investment level $y^{*}$. This comparison in turn hinges on whether the access charge $a$ is larger or smaller than the network marginal cost $k$. Observe that, with legal unbundling, the upstream firm cannot control the pricing decisions of its downstream subsidiaries. In 
the absence of downstream investment, the upstream firm induces a positive mark-up on the downstream market by decreasing the size of its network and at the same time increasing the (market clearing) access charge $a$, so that $a>k$. Introducing downstream investment, we obtain that a further effect of increasing $a$ above $k$ is to induce the downstream firm to invest more than would be socially optimal: $y^{*}<y^{e 2}$. This in turn implies that the downstream firm is able to sell more output for a given network size $l$ than with the optimal downstream investment level, which counteracts the effect of a higher access charge $a$ on $p$.

We have not been able to obtain analytically unambiguous results with respect to the comparison between optimal and $e 2$ levels of $a, y, l$ and $X$. We surmise that the new effect mentioned above mitigates only partially the direct effects described in section 3 , so that the most likely situation is the one where $a^{e 2}>k, y^{*}<y^{e 2}, l^{*}>l^{e 2}, p^{e 2}>p^{*}$ and $X^{*}>X^{e 2}$ - i.e., where the relationships between prices and quantities obtained in section 3 carry through to the case where downstream firms make an investment. We show in section 6.3 that it is the case for the numerical example we develop there.

Moving to the case with ownership separation $(e 0)$, observe that, unlike in previous sections, we can not be assured that the demand that prevails for downstream firms is increasing in the size of the network (i.e., that $\widetilde{x}_{i}^{\prime}(l)>0$ ). The reason is that a larger network, by decreasing the equilibrium access charge, reduces the incentives for downstream firms to invest in network-saving investments (see equation (15)), which means in turns that the firms end up with more network needs per unit of output, so that the larger network could accommodate a lower output level once the downstream decisions are factored in. In the case where $\widetilde{x}_{i}^{\prime}(l)>0$, we can replicate the argument of previous sections - namely, that downstream profit is increasing in network size - to show that the equilibrium network level under ownership separation is lower than the equilibrium level under legal separation and two subsidiaries: $l^{e 0}<l^{e 2}$. It is easy to see that $y^{e 0}>y^{*}$ because, with ownership unbundling, the only way for the upstream firm to make a profit is to charge an access price larger than its marginal cost, $a>k$.

Finally, the usual argument that the scenario $e 1$ is a convex combination of the scenarios $e 0$ and $e 2$ results in $l^{e 1}$ being intermediate between $l^{e 0}$ and $l^{e 2}$.

\subsection{A numerical example}

The new effects generated by the introduction of downstream investments have prevented us from reaching unambiguous analytical conclusions when comparing equilibrium and optimal levels of prices, network size and output. We 
therefore present a numerical example where the comparison of the equilibrium levels in the various scenarios is the same as in the previous sections.

We use the following functional forms

$$
\begin{aligned}
& C(x)=x^{2}, \\
& \beta(y)=1-\frac{\sqrt{y}}{10}, \\
& X(p)=100-5 p .
\end{aligned}
$$

We first study the case where $y$ is set exogenously equal to zero i.e., the case developed in section 3 . This allows us to show graphically the equilibrium and optimal levels of the network size $l$ and of output price $p$ as a function of the marginal network cost $k$. Figure 1 shows that $l^{e 0}<l^{e 1}<l^{e 2}<l^{*}$ while Figure 2 illustrates that $p^{e 0}>p^{e 1}>p^{e 2}>p^{*}$.

\section{[Insert Figures 1 and 2 around here]}

We now turn to the case where $y$ is chosen by the downstream firms. In Table 1, we compare the optimum and equilibrium values of $y, X, p, l$ and $a$ when $k$ is set equal to $5 .^{13}$

\begin{tabular}{|l|r|r|r|r|}
\hline & \multicolumn{5}{|c|}{ Scenarios } \\
\hline & $*$ & $e 2$ & \multicolumn{1}{c|}{$e 1$} & $e 0$ \\
\hline$y$ & 0.062 & 0.126 & 0.283 & 0.409 \\
\hline$X$ & 12.552 & 10.853 & 8.037 & 6.345 \\
\hline$p$ & 17.490 & 17.830 & 18.393 & 18.731 \\
\hline$l$ & 12.238 & 10.467 & 7.609 & 5.939 \\
\hline$a$ & \multicolumn{5}{|c|}{7.103} & 10.639 & 12.796 \\
\hline
\end{tabular}

Table 1 shows that we obtain the following relationship: $k<a^{e 2}<$ $a^{e 1}<a^{e 0}$. Intuitively, as the number of downstream firms owned by the upstream firm decreases, the upstream firm relies more and more on the access charge to increase its profit. At the limit, with ownership unbundling (case $e 0$ ), the access charge is the only way for the upstream firm to obtain revenues. In all scenarios, the equilibrium access charge is larger than its optimal level. It follows directly from this that we obtain $y^{*}<y^{e 2}<y^{e 1}<y^{e 0}$-i.e., the equilibrium level of downstream investment is too large and increases with ownership separation. The intuition is that downstream firms react to large

\footnotetext{
${ }^{13}$ We obtain the same qualitative results for any value of $k$ between 0 and 20 .
} 
access charges by over-investing in activities whose objective is to limit their network usage.

Table 1 also shows that $l^{*}>l^{e 2}>l^{e 1}>l^{e 0}$-i.e., the main result of the paper carries through to the case of downstream investments: the more ownership is unbundled, the larger is the incentive for the upstream firm to decrease its network size in order to raise its profit. We also obtain $p^{*}<p^{e 2}<$ $p^{e 1}<p^{e 0}$ : prices increase with ownership unbundling. Finally, observe that, even though downstream investment increases with ownership unbundling, total downstream quantity decreases with ownership unbundling: $X^{*}>X^{e 2}>$ $X^{e 1}>X^{e 0}$. In words, the main effect at work when ownership is unbundled is the incentive for the upstream firm to decrease its network size. The impact on the downstream investment mitigates only partially the consequences of a smaller network size, so that total quantity sold decreases with ownership unbundling.

\section{Conclusion}

In all the models that we have developed in this paper, we find that full control of the downstream industry by the upstream firm would be more efficient than separation. We obtain this result by assuming throughout the paper that the regulator has a strong control over the behavior in the downstream market. In particular, the regulator can completely prevent the network firm from favoring one of the downstream firms and, in the models of sections 3 and 4 , it can impose on the downstream firms that they behave competitively. On the other hand, it has less control over the long term decisions of the network, in our case new investment. Our model stresses the fact that, under these circumstances, making the upstream firm internalize the profits of its client can be a powerful method for inducing it to invest more. Even if the upstream firm owns only one of the two downstream firms, both firms benefit from this vertical integration.

Our model admittedly concentrates on only one impact of legal unbundling. Focusing on the consequences of incomplete contracting together with specific investment allows us to stress the advantages of legal unbundling. It is well known that vertical integration also has its costs and may be responsible for inefficiencies. To mention just two examples, there are problems of incentives within the organization and the vertical integration may facilitate anti-competitive practices. We are fully aware of these issues and acknowledge their significance. It is nevertheless our opinion that the effects mentioned in this paper are relevant and important enough to be of significance when assess- 
ing the desirability of legal unbundling. Put differently the issue of investment incentive ought not to be forgotten in the debate.

To analyze in more details the trade-offs involved in our approach, we would need to modify the model so that there are positive reasons why competition in the downstream market is beneficial. This would involve introducing explicitly some degree of asymmetric information, while preserving our emphasis on incomplete contracts and specific investment, and will be the topic for future research.

Finally let us return to the regulatory environment we consider. The scenario we have in mind reflects the (maybe utopian) world envisioned by the European directives where competition in downstream markets (along with competition policy) replaces to a large extent ex ante regulation. Clearly a well informed and efficient regulator could undo the problems we point out in this paper. However, it seems to us that this is not in the spirit of the projected reforms (at least in the European Union). Specifically, the ownership unbundling is meant to be part of the process which makes these reforms possible. In other words, we take a forward view on regulation and study if a specific organizational structure (along with admittedly minimalist regulation) provides appropriate incentives for network development. The negative answer we find means that ownership unbundling would have to be accompanied by some more stringent form of network size regulation - but then one may debate if it is the right avenue to deregulation.

\section{Appendix}

\section{Proof of Proposition 1}

(a) Under legal unbundling when the upstream firm owns both downstream firms, firm $U$ chooses $l$ to maximize

$$
\pi_{U}+\pi_{1}+\pi_{2}=\widetilde{a}(l) l-k l+X(\widetilde{p}(l))[\widetilde{p}(l)-\widetilde{a}(l)]-2 C\left(\frac{X(\widetilde{p}(l))}{2}\right) .
$$

We reorganize this optimization problem to obtain

$$
\begin{aligned}
\max _{l} & \pi_{U}+\pi_{1}+\pi_{2}=a l-k l+X(p)(p-a)-2 C\left(\frac{X(p)}{2}\right), \\
\text { s. t. } & p=C^{\prime}\left(\frac{X(p)}{2}\right)+a \\
& X(p)=l .
\end{aligned}
$$


Simplifying and using the inverse demand function yield

$$
\pi_{U}+\pi_{1}+\pi_{2}=l p(l)-2 C\left(\frac{l}{2}\right)-k l .
$$

Maximizing this expression with respect to $l$ gives the following first-order condition:

$$
p+l p^{\prime}=C^{\prime}\left(\frac{l}{2}\right)+k .
$$

Equation (A2) is the same condition that we would obtain if we assumed that the three firms acted as an integrated profit maximizing monopolist and maximized $p(l) l-2 C(l / 2)-k l$.

(b) (i) Comparing (1) and (A2), we obtain

$$
l^{e 2}<l^{*} \quad \text { and } \quad p^{e 2}>p^{*} .
$$

(b) (ii) We now turn to the situation where downstream and upstream ownerships are separated. When the upstream firm owns neither of the downstream firms, it sets the network size in order to maximize its own profits,

$$
\pi_{U}=\tilde{a}(l) l-k l .
$$

Using equations (2) and (3) together with the symmetry between the downstream firms, this optimization program can be rewritten as

$$
\begin{aligned}
\max _{l} & \pi_{U}=a l-k l \\
\text { s.t. } & p=C^{\prime}\left(\frac{X(p)}{2}\right)+a, \\
& X(p)=l .
\end{aligned}
$$

The two constraints imply

$$
a=p(l)-C^{\prime}\left(\frac{l}{2}\right)
$$

which we substitute in $\pi_{U}$ to obtain

$$
\begin{aligned}
\pi_{U} & =\left[p(l)-C^{\prime}\left(\frac{l}{2}\right)\right] l-k l, \\
& =\left[l p(l)-2 C\left(\frac{l}{2}\right)-k l\right]-2\left[C^{\prime}\left(\frac{l}{2}\right) \frac{l}{2}-C\left(\frac{l}{2}\right)\right] .
\end{aligned}
$$


Observe that the first term in the right hand side of (A4) corresponds to $\pi_{U}+\pi_{1}+\pi_{2}$ as defined in (A1). Because the two downstream firms are price takers, their downstream prices reflect their marginal costs: per unit of output, they each charge $C^{\prime}(l / 2)$ to their customers to reflect their costs. The second bracketed term represents the difference between the resulting revenue and their true cost. These are profits that the network must abandon to the downstream firms.

From (A4), we obtain

$$
\left.\frac{d \pi_{U}}{d l}\right|_{l=l^{e 2}}=-\frac{l^{e 2}}{2} C^{\prime \prime}\left(\frac{l^{e 2}}{2}\right)<0 .
$$

If the function $\pi_{U}$ is concave, which is the case if the revenue function is concave and if $C^{\prime \prime \prime} \geq 0,{ }^{14}$ this implies

$$
l^{e 0}<l^{e 2}<l^{*} .
$$

(b) (iii) We finally look at the intermediate situation where the upstream firm owns only one of the two downstream firms. We continue to assume legal unbundling between the upstream and the downstream firm it owns. One can proceed as in the previous section to obtain that

$$
\pi_{U}+\pi_{i}=\left[l p(l)-2 C\left(\frac{l}{2}\right)-k l\right]-\left[C^{\prime}\left(\frac{l}{2}\right) \frac{l}{2}-C\left(\frac{l}{2}\right)\right], \quad i=1,2 .
$$

Note that this objective function is a convex combination of the objectives in the previous two sections, which are given by (A1) and (A4):

$$
\pi_{U}+\pi_{i}=\frac{1}{2}\left(\pi_{U}+\pi_{1}+\pi_{2}\right)+\frac{1}{2} \pi_{U}, \quad i=1,2 .
$$

This in turn gives

$$
l^{e 0}<l^{e 1}<l^{e 2}<l^{*},
$$

given that the objective functions are concave. ${ }^{15}$

\footnotetext{
${ }^{14}$ Let $R(x)=p(x) x$ be the revenue function. From (A3), the second derivative of $\pi_{U}$ with respect to $l$ is

$$
R^{\prime \prime}(l)-C^{\prime \prime}\left(\frac{l}{2}\right)-\frac{1}{2} C^{\prime \prime \prime}\left(\frac{l}{2}\right) .
$$

It is negative if $R$ is concave and both $C^{\prime \prime}$ and $C^{\prime \prime \prime}$ are positive.

${ }^{15}$ This is a straightforward consequence of the concavity of the revenue function, and of the convexity of $C$ and $x C^{\prime}$ (whose second derivative is $2 C^{\prime \prime}+C^{\prime \prime \prime}$ ).
} 


\section{Proof of Proposition 2}

(a) Under the scenario $e 2$, the objective of the upstream firm is to find the network size $l$ that maximizes the sum of the three operators' profits:

$$
\max _{l} \pi_{U}+\pi_{1}+\pi_{2}=\left[\widetilde{x}_{1}(l)+\widetilde{x}_{2}(l)\right] \widetilde{p}(l)-C\left(\widetilde{x}_{1}(l)\right)-C\left(\widetilde{x}_{2}(l)\right)-k l .
$$

The first-order solution of this program is given by

$$
\begin{aligned}
\widetilde{p}(l)\left[\widetilde{x}_{1}^{\prime}(l)+\widetilde{x}_{2}^{\prime}(l)\right] & +\left[\widetilde{x}_{1}(l)+\widetilde{x}_{2}(l)\right] \widetilde{p}^{\prime}(l) \\
& -C^{\prime}\left(\widetilde{x}_{1}(l)\right) \widetilde{x}_{1}^{\prime}(l)-C^{\prime}\left(\widetilde{x}_{2}(l)\right) \widetilde{x}_{2}^{\prime}(l)-k=0 .
\end{aligned}
$$

To simplify this expression, we use (8) and

$$
\begin{aligned}
& \widetilde{p}^{\prime}(l)=\left[\widetilde{x}_{1}^{\prime}(l)+\widetilde{x}_{2}^{\prime}(l)\right] p^{\prime}\left(\widetilde{x}_{1}(l)+\widetilde{x}_{2}(l)\right), \\
& (1-\alpha) \widetilde{x}_{1}^{\prime}(l)+\widetilde{x}_{2}^{\prime}(l)=1,
\end{aligned}
$$

where (A7) and (A8) are obtained by differentiating, respectively, (8) and (6).

We substitute equations (8), (A7) and (A8) in (A6) and we obtain after simplifications that

$$
\begin{aligned}
& p\left(\widetilde{x}_{1}(l)+\widetilde{x}_{2}(l)\right)+\left(\widetilde{x}_{1}(l)+\widetilde{x}_{2}(l)\right) p^{\prime}\left(\widetilde{x}_{1}(l)+\widetilde{x}_{2}(l)\right) \\
& =\frac{\widetilde{x}_{1}^{\prime}(l)}{\widetilde{x}_{1}^{\prime}(l)+\widetilde{x}_{2}^{\prime}(l)} C^{\prime}\left(\widetilde{x}_{1}(l)\right)+\frac{\widetilde{x}_{2}^{\prime}(l)}{\widetilde{x}_{1}^{\prime}(l)+\widetilde{x}_{2}^{\prime}(l)} C^{\prime}\left(\widetilde{x}_{2}(l)\right)+\frac{k}{\widetilde{x}_{1}^{\prime}(l)+\widetilde{x}_{2}^{\prime}(l)} .
\end{aligned}
$$

Note that the factor dividing $k$ i the third term can alternatively be written as $1+\alpha \widetilde{x}_{1}^{\prime}(l)$.

This solution differs significantly from that obtained under symmetry in Section 3. To make this clear, let us compare (A9) with the first-order condition when the upstream firm is vertically integrated with the two downstream firms and has full control over output levels $x_{1}$ and $x_{2}$ (there is no legal unbundling). Denoting this solution by the superscript $V I$, we obtain

$$
\begin{aligned}
p\left(x_{1}^{V I}+x_{2}^{V I}\right)+\left(x_{1}^{V I}+x_{2}^{V I}\right) p^{\prime}\left(x_{1}^{V I}+x_{2}^{V I}\right) & =C^{\prime}\left(x_{1}^{V I}\right)+(1-\alpha) k \\
& =C^{\prime}\left(x_{2}^{V I}\right)+k .
\end{aligned}
$$

One can verify that a value of $a$ ensuring that $x_{1}^{V I}$ and $x_{2}^{V I}$ solve (4) and (5) exists only if $\alpha=0$ (i.e., under symmetry). ${ }^{16}$

\footnotetext{
${ }^{16}$ Combining (4) and (5) with (A10) and (A11) shows that this would require to find $a$ such that the following two equations hold

$$
\begin{aligned}
\left(x_{1}^{V I}+x_{2}^{V I}\right) p^{\prime}\left(x_{1}^{V I}+x_{2}^{V I}\right)+k(1-\alpha) & =a(1-\alpha) \\
\left(x_{1}^{V I}+x_{2}^{V I}\right) p^{\prime}\left(x_{1}^{V I}+x_{2}^{V I}\right)+k & =a,
\end{aligned}
$$

which is possible only when $\alpha=0$.
} 
(b) Observe that productive efficiency is maintained by the fully integrated firm, since marginal costs are the same at equilibrium for the two downstream operators. As for legal separation, note that (4) and (5) imply equal marginal costs only if $a=k$ which is not true in general.

(c) (i) Under ownership separation, the upstream firm maximizes its own profit, which can be expressed as

$$
\pi_{U}=\left(\pi_{U}+\pi_{1}+\pi_{2}\right)-\left(\pi_{1}+\pi_{2}\right)
$$

We can also rewrite the profit functions of the two downstream firms as

$$
\begin{aligned}
\pi_{1} & =\widetilde{x}_{1}(l)[\widetilde{p}(l)-(1-\alpha) \widetilde{a}(l)]-C\left(\widetilde{x}_{1}(l)\right), \\
& =\widetilde{x}_{1}(l) C^{\prime}\left(\widetilde{x}_{1}(l)\right)-C\left(\widetilde{x}_{1}(l)\right), \\
\pi_{2} & =\widetilde{x}_{2}(l)[\widetilde{p}(l)-\widetilde{a}(l)]-C\left(\widetilde{x}_{2}(l)\right), \\
& =\widetilde{x}_{2}(l) C^{\prime}\left(\widetilde{x}_{2}(l)\right)-C\left(\widetilde{x}_{2}(l)\right) .
\end{aligned}
$$

Differentiating profits with respect to network size, we then obtain

$$
\begin{aligned}
& \pi_{1}^{\prime}=\widetilde{x}_{1}(l) C^{\prime \prime}\left(\widetilde{x}_{1}(l)\right) \widetilde{x}_{1}^{\prime}(l)>0 \\
& \pi_{2}^{\prime}=\widetilde{x}_{2}(l) C^{\prime \prime}\left(\widetilde{x}_{2}(l)\right) \widetilde{x}_{2}^{\prime}(l)>0 .
\end{aligned}
$$

Using equation (A12), we show

$$
\begin{aligned}
\pi_{U}^{\prime}\left(l^{e 2}\right) & =\left[\pi_{U}^{\prime}\left(l^{e 2}\right)+\pi_{1}^{\prime}\left(l^{e 2}\right)+\pi_{2}^{\prime}\left(l^{e 2}\right)\right]-\left[\pi_{1}^{\prime}\left(l^{e 2}\right)+\pi_{2}^{\prime}\left(l^{e 2}\right)\right], \\
& =0-\left[\pi_{1}^{\prime}\left(l^{e 2}\right)+\pi_{2}^{\prime}\left(l^{e 2}\right)\right]<0,
\end{aligned}
$$

which, by concavity of the function $\pi_{U}$, implies

$$
l^{e 0}<l^{e 2}
$$

(c) (ii) In the $e 11$ scenario, the objective of the upstream operator is to maximize

$$
\pi_{U}=\left(\pi_{U}+\pi_{1}+\pi_{2}\right)-\pi_{2},
$$

which allows us to use the same argument as in the $e 0$ scenario where ownership is totally unbundled between the upstream and downstream segments. More precisely, with $\pi_{U}$ given by equation (A13), we obtain that

$$
\pi_{U}^{\prime}\left(l^{e 2}\right)=-\pi_{2}^{\prime}<0
$$

and that

$$
\pi_{U}^{\prime}\left(l^{e 0}\right)=\pi_{1}^{\prime}>0
$$


so that, provided that $\pi_{U}$ is concave in $l$, we obtain

$$
l^{e 0}<l^{e 11}<l^{e 2}
$$

Similarly, one can show that

$$
l^{e 0}<l^{e 12}<l^{e 2}
$$

\section{Proof of Proposition 3}

(i) Under legal separation with two subsidiaries, the upstream firm internalizes the downstream profit and solves

$$
\begin{aligned}
\max _{l} & \pi_{U}+\pi_{1}+\pi_{2}=a l-k l+X(p)[p-a-c] \\
\text { s.t. } & p=a+c-\frac{l}{2} \tilde{p}^{\prime}(l), \\
& X(p)=l .
\end{aligned}
$$

After simplification and using the inverse demand function, we obtain

$$
\pi_{U}+\pi_{1}+\pi_{2}=l(\tilde{p}(l)-c-k)
$$

whose maximization with respect to $l$ gives the condition

$$
\tilde{p}+l \tilde{p}^{\prime}=c+k .
$$

This condition is the usual profit-maximization solution of a monopoly, equalizing marginal revenue and marginal cost.

Observe that the second order condition for total (downstream plus upstream) profit maximization is given by

$$
2 \tilde{p}^{\prime}+l \tilde{p}^{\prime \prime}<0
$$

We will use this result later.

Comparing (9) and (A15), we obtain that $l^{e 2}<l^{*}$ and $p^{e 2}>p^{*}$.

(ii) If ownership is separated between upstream and downstream segments of the markets, the upstream firm chooses the network size that maximizes

$$
\pi_{U}=\tilde{a}(l) l-k l
$$


We can rewrite the optimization problem as

$$
\begin{array}{ll}
\max _{l} & \pi_{U}=a l-k l \\
\text { s.t. } & p=a+c-\frac{l}{2} p^{\prime}(l), \\
& X(p)=l .
\end{array}
$$

We obtain after substitution that

$$
\pi_{U}=[p(l)-c-k] l+\frac{l^{2}}{2} p^{\prime}(l) .
$$

The first term in the right hand side of (A17) is equal to the total profit $\pi_{U}+\pi_{1}+\pi_{2}$ as specified by equation (A14) when the upstream firm owns both downstream firms. This implies

$$
\left.\frac{d \pi_{U}}{d l}\right|_{l=l^{e 2}}=l^{e 2}\left[p^{\prime}\left(l^{e 2}\right)+\frac{l^{e 2}}{2} p^{\prime \prime}\left(l^{e 2}\right)\right]<0,
$$

where the inequality is a consequence of condition (A16). Therefore, by concavity of $\pi_{U}$,

$$
l^{e 0}<l^{e 2}
$$

(iii) See the text for the proof that

$$
l^{e 0}<l^{e 1}<l^{e 2} .
$$

\section{Proof of Proposition 4}

(a) When the upstream firm owns the two downstream firms, it maximizes the sum of its profit, $\pi_{U}$ and of profits of the two downstream firms, $\pi_{1}$ and $\pi_{2}$ :

$$
\begin{aligned}
\pi_{U}+\pi_{1}+\pi_{2}= & \widetilde{a}(l) l-k l+X(\widetilde{p}(l))[\widetilde{p}(l)-\beta(\tilde{y}(l)) \widetilde{a}(l)] \\
& -2 C\left(\frac{X(\widetilde{p}(l))}{2}\right)-\tilde{y}(l) X(\tilde{p}(l))
\end{aligned}
$$

where $\tilde{a}(l), \tilde{y}(l)$ and $\tilde{p}(l)$ are the solutions to equations (15) to (17). 
We reorganize this optimization problem to obtain

$$
\max _{l} \pi_{U}+\pi_{1}+\pi_{2}=a l-k l+X(p)(p-\beta(y) a)-2 C\left(\frac{X(p)}{2}\right)-y X(p)
$$

s. t. $p=C^{\prime}\left(\frac{X(p)}{2}\right)+a \beta(y)+y$,

$$
\begin{aligned}
& l=\beta(y) X(p), \\
& 1=-\beta^{\prime}(y) a .
\end{aligned}
$$

After simplification, and using the inverse demand function, we obtain

$$
\pi_{U}+\pi_{1}+\pi_{2}=\frac{l}{\beta(y)} \tilde{p}(l)-2 C\left(\frac{l}{2 \beta(y)}\right)-k l-\frac{y l}{\beta(y)}
$$

whose maximization with respect to $l$ gives the following first-order condition

$$
\tilde{p}(l)+l \tilde{p}^{\prime}(l)=C^{\prime}\left(\frac{l}{2 \beta(y)}\right)+y+k \beta(y),
$$

where $y$ is determined by

$$
\beta^{\prime}(y) a=-1 .
$$

This corresponds to the profit-maximizing condition of a monopoly, where marginal revenue equals total marginal cost. In order to compare with the socially optimal price, we denote as usual the equilibrium levels with the $e 2$ superscript and reformulate (A18) into

$$
p^{e 2}-C^{\prime}\left(\frac{l^{e 2}}{2 \beta\left(y^{e 2}\right)}\right)=y^{e 2}+k \beta\left(y^{e 2}\right)-l^{e 2} \tilde{p}^{\prime}\left(l^{e 2}\right) .
$$

We now compare the right hand sides of (13) and (A19) term by term. The sum of the first two terms is the (per unit of output) network cost, including the investment cost. Note that $y^{*}+k \beta\left(y^{*}\right)<y^{e 2}+k \beta\left(y^{e 2}\right)$ if $a \neq k$, since $y^{*}$ precisely minimizes $y+k \beta(y)$. This calls for a profit-maximizing price $p^{e 2}$ larger than its optimal level, because in the $e 2$ scenario the downstream firms base their investment decision on the access charge rather than the marginal social cost $k$, and end up (when $a \neq k$ ) with a social marginal cost that is larger than its socially optimal level. The third term in (A19) pushes $p^{e 2}$ in the same direction.

(b) (i) Recall that the objective of the upstream firm with ownership unbundling can be expressed as

$$
\pi_{U}=\left(\pi_{U}+\pi_{1}+\pi_{2}\right)-\left(\pi_{1}+\pi_{2}\right)
$$


We can also rewrite the profit functions of the two downstream firms as

$$
\begin{aligned}
\pi_{i} & =\widetilde{x}_{i}(l)[\widetilde{p}(l)-\beta(\tilde{y}(l)) \widetilde{a}(l)-\tilde{y}(l)]-C\left(\widetilde{x}_{i}(l)\right), \\
& =\widetilde{x}_{i}(l) C^{\prime}\left(\widetilde{x}_{i}(l)\right)-C\left(\widetilde{x}_{1}(l)\right)
\end{aligned}
$$

where

$$
\widetilde{x}_{i}(l)=\frac{l}{2 \beta(\tilde{y}(l))} .
$$

Differentiating profits with respect to network size, we obtain

$$
\pi_{i}^{\prime}=\widetilde{x}_{1}(l) C^{\prime \prime}\left(\widetilde{x}_{1}(l)\right) \widetilde{x}_{1}^{\prime}(l)
$$

where

$$
\widetilde{x}_{i}^{\prime}(l)=\frac{2 \beta(\tilde{y}(l))-2 l \beta^{\prime}(y) \tilde{y}^{\prime}(l)}{4 \beta^{2}(\tilde{y}(l))}
$$

is of an ambiguous sign since $\beta^{\prime}(y)<0$ and $\tilde{y}^{\prime}(l)<0$.

Observe that, if $\widetilde{x}_{i}^{\prime}(l)>0$, then we can use the same reasoning as in section 4 to obtain, provided that the objective function $\pi_{U}$ is concave,

$$
l^{e 0}<l^{e 2}
$$

In that case, we would also have

$$
l^{e 0}<l^{e 1}<l^{e 2}
$$

because the objective in the case $e 1$ is a convex combination of the objectives in the scenarios $e 0$ and $e 2$, with the same constraints in all three cases. Provided that the objective is concave, we then obtain that the $e 1$ levels of the variables

$p, y$, and $l$ should be in between their equilibrium levels in scenarios $e 0$ and $e 2$.

\section{References}

Alchian, A. and Demsetz, H.(1972), 'Production, Information Costs, and Economic Organization', American Economic Review 62, 777-795.

Bolle, F. and Breitmoser, Y. (2006), 'On the Allocative Efficiency of Ownership Unbundling', Europa-Universität Viadrina, Frankfurt (Oder), Discussion Paper 255. 
Brito, D., Pereira, P. and Vareda, J. (2010), 'Can Vertical Separation Reduce Non-Price Discrimination and Increase Welfare?', Proceedings of the 4th ACORN-REDECOM Conference Brasilia, D.F., May 14-15th.

Buehler, S., Schmutzler, A. and Benz, M-A. (2004), 'Infrastructure quality in deregulated industries: is there an underinvestment problem?', International Journal of Industrial Organization 22, 253-267.

Fiocco, R. (2011), 'The design of ownership structure in a vertically related market with unknown upstream costs', HumboldtUniversität zu Berlin, mimeo.

Grossman, S. J. and Hart, O. D. (1986), 'The costs and benefits of ownership: A theory of vertical and lateral integration', Journal of Political Economy 94(4), 691-719.

Guthrie, G.(2006), 'Regulating infrastructure: the impact on risk and investment', Journal of Economic Literature 4, 925-972.

Höffler, F. andKranz, S.(2011a), 'Legal unbundling can be a golden mean between vertical integration and ownership separation', International Journal of Industrial Organization 29, 576-588.

Höffler, F. andKranz, S.(2011b), 'Imperfect legal unbundling of monopolistic bottlenecks', Journal of Regulatory Economics, 39(3), 273-292.

Sibley, D. S. andWeissman, D.L.(1998), 'Raising rival"'s costs: the entry of an upstream monopolist into downstream markets', Informational Economics and Policy 10, 451-470.

van Koten, S. (2008), 'The effects of vertical integration on auction outcomes in the EU and US electricity markets', mimeo, CERGEI-EI.

Vickers, J.(1995), 'Competition and Regulation in Vertically Related Markets', Review of Economic Studies 62, 1-17. 
Figure 1 : Network size as a function of network cost

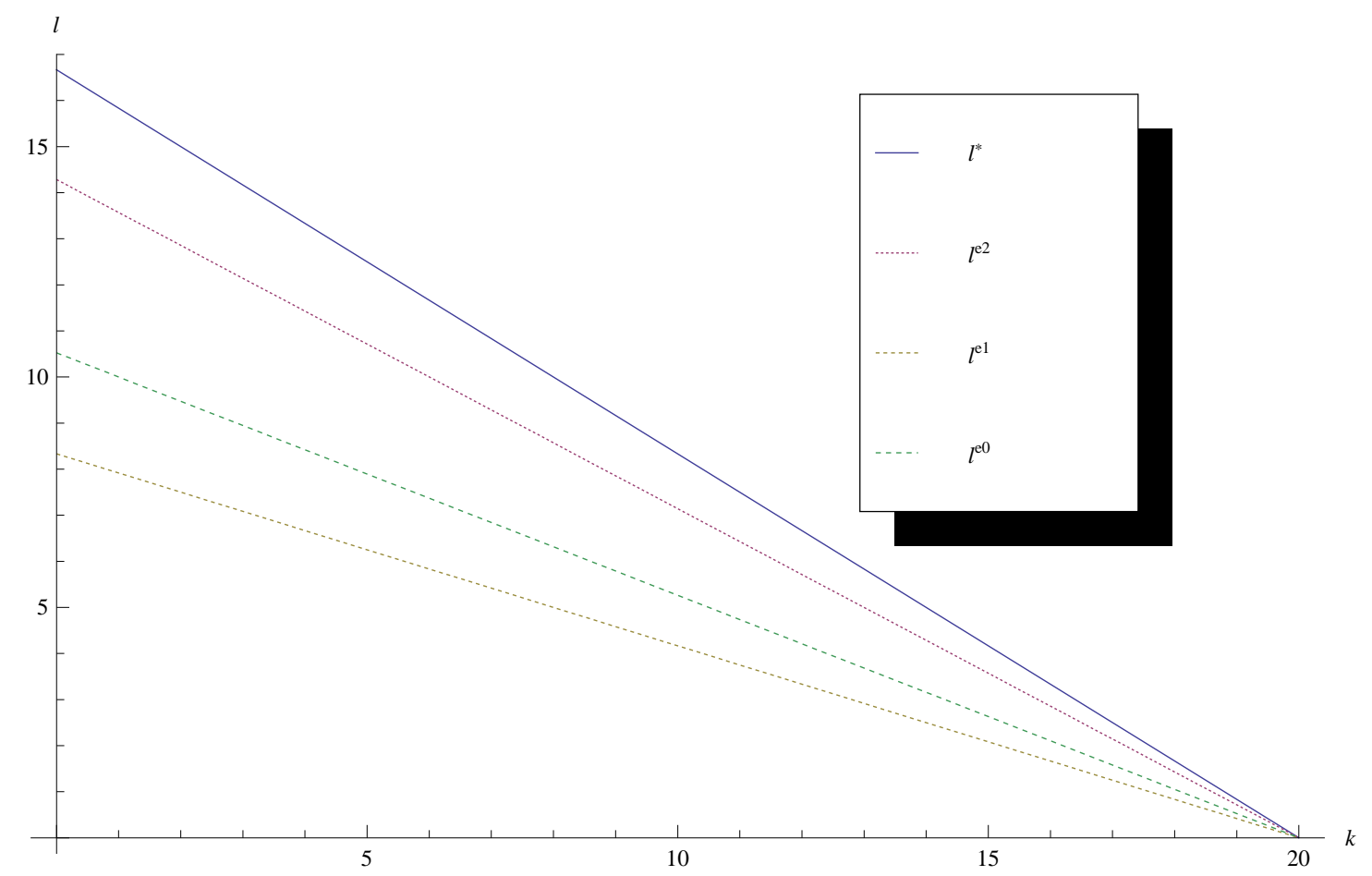

Figure 2 : Output price as a function of network cost

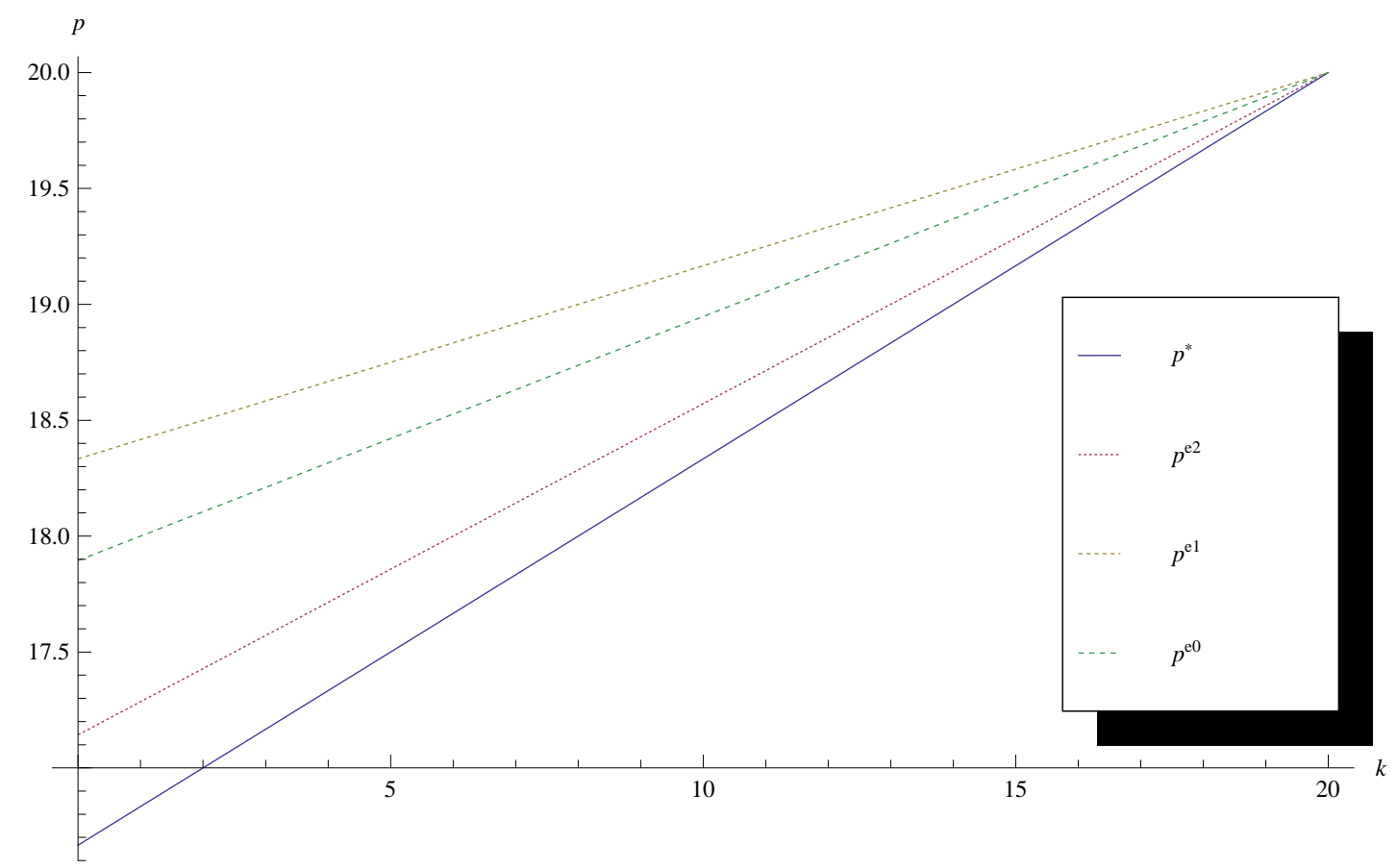

